\title{
SECAGEM DE SOLUÇÕES FILMOGÊNICAS DE AMIDO DE FRUTA-DE-LOBO (Solanum lycocarpum St. Hil.) E PROPRIEDADES FÍSICAS DOS FILMES EM FUNÇÃO DO PLASTIFICANTE E DA TEMPERATURA
}

\author{
MARIANAFERREIRA OLIVEIRA PRATES* \\ DIEGO PALMIRO RAMIREZASCHERI ${ }^{* *}$
}

\begin{abstract}
No presente trabalho estudou-se o efeito da temperatura de secagem (TS) e da concentração de sorbitol (CS) nas características de secagem de soluções filmogênicas (SF) de amido de fruta-delobo e na espessura, permeabilidade ao vapor de água (Pva) e solubilidade dos filmes biodegradáveis (FB) elaborados. As SF foram preparadas com $2 \%$ de amido e variações na CS de 0,1; 0,2 e 0,3\%, e secas em estufa com circulação de ar nas temperaturas de 33,38 e $43^{\circ} \mathrm{C}$. Adotou-se delineamento experimental inteiramente casualizado com esquema fatorial $3^{2}$, sendo 3 níveis de cada um dos fatores CS e TS. O teor de água inicial das SF foi avaliado por meio de análise de variância e as médias comparadas pelo teste de Tukey. As curvas de secagem foram ajustadas pelos modelos empíricos de Newton, Page, Henderson \& Pabis e Midilli. Foram obtidos modelos para cada variável resposta: difusividade efetiva (Deff), espessura, Pva e solubilidade em água pela metodologia de superfície de resposta. O teor de água inicial das SF variou com a CS, sendo que seu aumento provocou redução dessa característica, não sendo influenciado pela TS. O modelo de Midilli obteve melhor ajuste aos dados experimentais de secagem das SF. O aumento da CS e da TS causou incremento na Deff das SF e na Pva dos FB, sendo verificado efeito linear. A solubilidade dos filmes estudados foi afetada positivamente e linearmente pelo aumento da CS e pela redução da TS. Não foi verificado efeito sobre a espessura dos filmes.
\end{abstract}

* Mestranda em Engenharia Agrícola, Unidade de Ciências Exatas e Tecnológicas (UnUCET), Universidade Estadual de Goiás (UEG), Anápolis, GO (e-mail: fo.mariana@gmail.com).

** Doutor em Engenharia de Alimentos, Docente, Curso de Mestrado em Engenharia Agrícola, UnUCET/ UEG, Anápolis, GO (e-mail: ascheridpr@gmail.com). 


\section{INTRODUÇÃO}

O aumento da população e da economia mundial tem resultado no crescimento da produção de lixo, cuja composição é, em grande parte, de plásticos derivados do petróleo (LAROTONDA et al., 2004). O consumo desses materiais poliméricos no Brasil e no mundo vem crescendo há décadas, devido às suas características de baixo custo, boa resistência mecânica, impermeabilidade e transparência (GORNI, 2006). Esse aumento tem tornado necessária a produção de substitutos biodegradáveis. Nesse contexto, os plásticos ambientalmente degradáveis (PAD) abrem opção adicional de gerenciamento de resíduos. A degradabilidade desses materiais, após seu uso permite que eles permaneçam no ciclo natural do carbono (INNOCENTNI-MEI e MARIANI, 2005).

Uma das alternativas para minimizar o consumo de plásticos derivados do petróleo é a utilização de polímeros provenientes de fontes vegetais auto-sustentáveis como os amidos de raízes e tubérculos, de sementes e frutas. O amido tornou-se uma fonte promissora para obtenção de plásticos biodegradáveis, devido ao baixo custo de produção e obtenção a partir de recursos renováveis (THIRÉ et al., 2004). O polímero apresenta muitas possibilidades de modificação química e física e origina filmes e revestimentos resistentes (SHIMAZU, MALI e GROSSMANN, 2007).

Espécies de frutos das regiões do Cerrado brasileiro apresentam potencial de uso quanto ao teor de amido e são pouco exploradas. Os frutos da fruta-de-lobo (Solanum lycocarpum Saint Hillaire), por exemplo, podem conter mais de $20 \mathrm{~g}$ de amido por $100 \mathrm{~g}$ de polpa da fruta (OLIVEIRA-JÚNIOR et al., 2004; SANTOS, 2009).

A fruta-de-lobo pertence à família Solanaceae, cresce e se desenvolve em condições ambientais desfavoráveis, tais como terras ácidas e pobres em nutrientes. É capaz de suportar clima árido e períodos de seca prolongados, resistindo ainda a ciclos anuais de queimadas feitas pelo homem. Prolifera rapidamente em vegetações do tipo campo sujo, cerrado e cerradão. A planta pode apresentar de 40 a 100 frutos, cuja massa por fruto pode variar de 400 a $900 \mathrm{~g}$ (CAMPOS, 1994). Pelo seu potencial de crescimento, propagação e produção de frutos, a fruta-de-lobo pode ser empregada para a produção de amido e esse pode ser pesquisado quanto a suas propriedades formadoras de filmes biodegradáveis.

A obtenção dos filmes ou coberturas biodegradáveis está baseada na técnica de espalhamento (casting) em que o amido passa por dispersão, solubilização e gelatinização em solvente, com formação de solução filmogênica (VILPOUX e AVEROUS, 2003).

A elaboração dos biofilmes normalmente exige o uso de plastificantes, geralmente poliois, que reduzem as interações intermoleculares entre as cadeias adjacentes do amido, resultando no aumento da mobilidade dessas cadeias e, consequentemente em materiais flexíveis (GONTARD, GUILBERT e CUQ, 1993; LOURDIM et al., 1997). O sorbitol é muito utilizado na elaboração de soluções filmogênicas em combinação com o amido (SHIMAZU, MALI e GROSSMANN, 2007).

Os filmes se formam assim que a solução filmogênica é aplicada num suporte e o solvente é evaporado por meio de secagem. Após a gelatinização dos grânulos do amido em excesso de água, a amilose e a amilopectina se dispersam na solução que durante a secagem se rearranjam formando uma matriz polimérica (MALI et al., 2004).

Durante o processo de secagem ocorre a transferência da água das soluções filmogênicas por difusão molecular. Segundo KESTER e FENNEMA(1986), esse processo pode ser devido ao movimento do solvente para a superfície da estrutura do filme e sua adsorção dentro da matriz polimérica, mediante difusão através dos poros formados pelo movimento da cadeia polimérica do filme, ou na própria elaboração e pela evaporação a partir da superfície dos filmes e sua consequente dispersão no ar.

Geralmente, a água é utilizada como solvente na elaboração das soluções filmogênicas e, após seu processo de secagem, a quantidade de água nos filmes gerados é menor que no amido puro, sugerindo que os plastificantes ligam-se fortemente ao amido, o que desloca a água quando as amostras estão em ambiente de baixa umidade (GONTARD et al., 1993). Esse fato pode ser relativo, pois KESTER e FENNEMA (1986) afirmaram que o grau de coesão das ligações durante a formação dos filmes depende das propriedades estruturais poliméricas, da formulação, da temperatura, do efeito do solvente e do efeito plastificante. 
CARVALHO (1997), no desenvolvimento e caracterização de biofilmes à base de gelatina, constatou que os biofilmes apresentavam melhores características mecânicas quando as soluções filmogênicas eram secas a $35^{\circ} \mathrm{C}$ durante período de $24 \mathrm{~h}$. Em temperaturas de secagem acima de $35^{\circ} \mathrm{C}$, a autora observou que os filmes fundem-se e abaixo desse patamar tornam-se excessivamente pegajosos. O mesmo pode ocorrer com o tempo de exposição ao processo de secagem, independentemente da temperatura. Em filmes com alto teor de água ocorre a proliferação de microrganismos e, em baixos teores, os filmes se tornam quebradiços e pouco flexíveis.

Alguns trabalhos foram realizados visando a elaboração de filmes biodegradáveis utilizando o amido do fruta-de-lobo e plastificantes, como o glicerol e sorbitol (FREITAS, RODRIGUES e ASCHERI, 2007; SANTOS, 2009), porém em nenhum deles foi considerado o efeito da concentração de plastificante e da temperatura de secagem na sua elaboração.

No presente trabalho foram estudadas as características de secagem das soluções filmogênicas e de algumas propriedades físicas (espessura, permeabilidade ao vapor de água e solubilidade) dos filmes biodegradáveis em função da concentração de sorbitol e da temperatura de secagem durante a elaboração de filmes de amido de fruta-de-lobo.

\section{MATERIAL E MÉTODOS}

Os frutos de fruta-de-lobo foram colhidos no início do estágio de maturação no perímetro rural do município de São Miguel do Passa Quatro (Goiás). Selecionaram-se os frutos com ausência de partes danificadas ou podres, que foram embalados em sacos de juta e transportados para o Laboratório de Química da Unidade Universitária de Ciências Exatas e Tecnológicas da Universidade Estadual de Goiás (Anápolis-GO) para a extração do amido.

Depois de lavados com água corrente, descascados com faca de aço inoxidável, picados e imersos por 10 min em solução de metabissulfito de sódio a 0,05\% para prevenir o escurecimento do amido, os frutos foram moídos em moinho de facas tipo "CROTON", modelo MA580 (MARCONI, Piracicaba, Brasil) com malha de $2,0 \mathrm{~mm}$ e água abundante. $O$ amido contido na polpa foi extraído por peneiragens sucessivas, usando-se peneiras de malhas finas de diâmetros entre 0,5 e 0,037 mm.

O amido extraído foi lavado com álcool etílico absoluto para remoção de substâncias gordurosas, filtrado à vácuo e seco em estufa de circulação de ar a $45^{\circ} \mathrm{C}$ até massa constante. Após resfriado em dessecadores até temperatura ambiente, o amido foi acondicionado em frascos para sua posterior utilização.

O teor de água do amido foi determinado segundo a metodologia descrita pela AOAC (2000) em estufa Fanem a $105^{\circ} \mathrm{C}$.

Os tratamentos de elaboração e secagem das soluções filmogênicas foram dispostos em esquema fatorial $3^{2}$, com três níveis de concentração de sorbitol $(0,1 ; 0,2$ e $0,3 \%)$ e três níveis de temperatura $\left(33,38 \mathrm{e} 43^{\circ} \mathrm{C}\right)$ em delineamento inteiramente casualizado. Foram realizados 9 tratamentos com três repetições por tratamento.

A Tabela 1 mostra os valores reais dos níveis dos fatores independentes utilizados. As soluções filmogênicas (SF) foram preparadas com $2 \mathrm{~g}$ de amido (em base seca) para $100 \mathrm{~g}$ de água destilada, adicionadas de sorbitol em concentrações que variaram de acordo com a Tabela 1.

\section{TABELA 1 - NÍVEIS DOS FATORES CODIFICADOS E REAIS PARA O PLANEJAMENTO EXPERIMENTAL DO PREPARO E SECAGEM DAS SOLUÇÕES FILMOGÊNICAS}

\begin{tabular}{cccc}
\hline \multirow{2}{*}{ Fatores independentes } & \multicolumn{3}{c}{ Nível } \\
\cline { 2 - 4 } & -1 & 0 & +1 \\
\hline Concentração de sorbitol $(\%)$, CS & 0,1 & 0,2 & 0,3 \\
Temperatura de secagem $\left({ }^{\circ} \mathrm{C}\right)$, TS & 33 & 38 & 43 \\
\hline
\end{tabular}


Para o preparo das soluções filmogênicas foi necessário determinar a temperatura e o tempo de gelatinização do amido. Esses parâmetros foram obtidos no Laboratório de Reologia da Embrapa Agroindústria de Alimentos (EMBRAPA/RJ), utilizando-se Determinador Rápido de Viscosidade (RVA) segundo o método de ASCHERI et al. (2006), Para este fim, preparou-se solução aquosa de 3,0 g de amido (em base seca) em $25 \mathrm{~mL}$ de água destilada que foi submetida à leitura no RVA. Manteve-se a temperatura inicial a $50^{\circ} \mathrm{C}$ por 1 min seguido de aquecimento com taxa de $6^{\circ} \mathrm{C}$ por minuto até $95^{\circ} \mathrm{C}$, permanecendo constante por $5 \mathrm{~min}$. A pasta foi resfriada até $50^{\circ} \mathrm{C}$ com taxa de $6^{\circ} \mathrm{C}$ por minuto. Do gráfico obtido foram detectados a temperatura e o tempo de viscosidade máxima, utilizados para gelatinização do amido.

As soluções filmogênicas (SF), após preparadas, foram aquecidas em banho-maria à temperatura e tempo de viscosidade máxima estabelecidos no RVA, sob agitação constante.

A secagem foi realizada em estufa com circulação de ar forçada (MARCONI MA 030), sendo transferidos $10 \mathrm{~mL}$ das SF ainda quentes para placas de Petri de acrílico com diâmetro interno de $8,8 \mathrm{~cm}$ que foram acondicionadas nas bandejas da estufa. As temperaturas de secagem estabelecidas no delineamento experimental estão apresentadas na Tabela 1.

Acompanhou-se o processo de secagem por meio da perda de massa das SF, medida em balança digital com capacidade de $200 \mathrm{~g}$ e precisão de 0,0001 g. O monitoramento da massa ocorreu em intervalos regulares de 30 min até a massa atingir o equilíbrio higroscópico, detectado quando pelo menos três pesagens consecutivas apresentaram o mesmo valor até a terceira casa decimal. Os filmes biodegradáveis resultantes foram armazenados em dessecadores contendo sílica-gel à temperatura de $21 \pm 2^{\circ} \mathrm{C}$ por $24 \mathrm{~h}$.

A perda de massa das SF, registrada em planilhas de controle, foi posteriormente utilizada para a determinação das curvas de secagem.

O teor de água em base seca $(X)$ e a razão de umidade foram calculados de acordo com as Equações 1 e 2, respectivamente:

Em que:

$$
x=\frac{\left(m_{\mathrm{U}}-m_{\mathrm{S}}\right)}{m_{\mathrm{S}}}
$$

$\mathrm{m}_{\mathrm{u}}$ e $\mathrm{m}_{\mathrm{s}}=$ massas da amostra úmida e seca, respectivamente, em $\mathrm{kg} \mathrm{kg}^{-1}$.

$$
R U=\frac{x-x_{e}}{x_{0}-x_{e}}
$$

Em que:

$\mathrm{X}_{0}$ e $\mathrm{X}_{\mathrm{e}}=$ teores de água inicial e de equilíbrio higroscópico de secagem, respectivamente $\left(\mathrm{em} \mathrm{kg} \mathrm{kg}^{-1}\right)$.

No presente estudo considerou-se que o valor do teor de água de equilíbrio higroscópico das SF foi relativamente pequeno devido à baixa umidade relativa do ar de secagem quando comparado aos valores de $X$ ou $X_{0}$, podendo a Equação 2 ser resumida (DOYMAZ e PALA, 2002) como:

$$
\mathrm{RU}=\frac{\mathrm{x}}{\mathrm{x}_{0}}
$$

O modelo da difusão líquida, que é a solução analítica para a segunda lei de Fick foi utilizada para descrever o comportamento de secagem das soluções filmogênicas. Assumiu-se também que o sistema se comporta como uma placa fina em que a água migra somente por difusão, desprezando-se qualquer efeito pelo encolhimento do material, e que a temperatura e o coeficiente de difusão efetivo são constantes ao longo do tempo de secagem. Portanto, a Lei de Fick para o processo de difusão pode ser expressa (BARONI e HUMBINGER, 1998) por: 


$$
R U=\sum_{n=0}^{n=1} \frac{8}{(2 n+1)^{2} \pi^{2}} \exp \left(\frac{-D_{\text {eff }}(2 n+1)^{2} \pi^{2} t}{4 L^{2}}\right)
$$

Em que:

$L=a$ espessura do filme; $t=0$ tempo de secagem, $D_{\text {eff }}=$ a difusividade efetiva, $\pi=a$ 3,1416 e $n=0$ número de termos na série.

Quando a espessura da amostra é muito pequena ( $<0,005 \mathrm{~m})$ e o tempo de secagem é relativamente longo, considera-se apenas o primeiro termo da lei de Fick.

Os modelos matemáticos de Henderson \& Pabis, Newton, Page e Midilli foram utilizados para predizer as curvas de razão de umidade em função do tempo. Esses modelos estão descritos nas Equações de 5 a 8, respectivamente:

$$
\begin{gathered}
\mathrm{RU}=\operatorname{a} \cdot \exp (-\mathrm{kt}) \\
\mathrm{RU}=\exp (-\mathrm{k} \cdot \mathrm{t}) \\
\mathrm{RU}=\exp \left(-k \mathrm{t}^{\mathrm{n}}\right) \\
\mathrm{RU}=\mathrm{a} \cdot \exp \left(-k \mathrm{t}^{\mathrm{n}}\right)+\mathrm{b} \cdot \mathrm{t}
\end{gathered}
$$

Em que:

$\mathrm{t}=\mathrm{o}$ tempo de secagem $(\mathrm{em} \mathrm{h}) ; \mathrm{a}, \mathrm{b}$ e $\mathrm{n}=$ constantes de ajuste do modelo e a constante de secagem $\mathrm{k}\left(\mathrm{em} \mathrm{h} \mathrm{h}^{-1}\right)$ foi descrita como:

$$
k=\frac{D_{\text {eff }} \pi^{2}}{4 L^{2}}
$$

Os filmes biodegradáveis (FB) elaborados foram caracterizados quanto à espessura, permeabilidade ao vapor de água (Pva) e solubilidade em água.

Com o auxílio de micrômetro manual Tesa Isomaster ${ }^{\circledR}( \pm 0,01 \mathrm{~mm})$, modelo Swiss, mediu-se a espessura dos FB em nove pontos radialmente equitativos (VICENTINI, 2003).

A Pva foi determinada gravimetricamente, segundo teste da ASTM (1995), modificado por Gontard, Guilbert e Cuq (1992), sendo calculada por meio da Equação 10:

$$
P v a=\frac{G \cdot V}{\operatorname{A} T \cdot\left(p_{1}-p_{2}\right)}
$$

Em que:

Pva = a permeabilidade ao vapor de água $\left(\mathrm{g} \mathrm{m}^{-1} \mathrm{~s}^{-1} \mathrm{~Pa}^{-1}\right) ; \mathrm{G}=0$ ganho de massa $(\mathrm{g})$ da célula durante $24 \mathrm{~h} ; \mathrm{V}=\mathrm{a}$ espessura $(\mathrm{m})$ média do filme; $\mathrm{A}=\mathrm{a}$ área $\left(\mathrm{m}^{2}\right)$ de permeação do filme; $\mathrm{T}=\mathrm{o}$ tempo $(\mathrm{s}) \mathrm{e}$ $\mathrm{p}_{1}-\mathrm{p}_{2}=\mathrm{o}$ gradiente de pressão $(\mathrm{Pa})$ de vapor entre as superfícies do filme.

A solubilidade em água foi determinada segundo metodologia proposta por Gontard Guilbert e Cuq (1992), com modificações. Inicialmente, a massa seca de uma amostra de filme com $2 \mathrm{~cm}$ de diâmetro foi determinada em função de sua umidade em estufa (MARCONI MA 030) mantida a $105^{\circ} \mathrm{C}$ por 24 h. A amostra foi, então, imersa em $50,0 \mathrm{~mL}$ de água destilada e o sistema mantido sob agitação a $175 \mathrm{rpm}$, a $25^{\circ} \mathrm{C}$, durante $24 \mathrm{~h}$, utilizando-se banho-maria tipo Dubnoff com agitação pendular. Após esse período, as amostras foram retiradas da água e a massa seca determinada nas mesmas condições descritas para obtenção da massa seca inicial. A solubilidade em água foi expressa em porcentagem de material solubilizado, calculada a partir dos resultados em triplicata, por meio da Equação 11: 


$$
\text { Solubilidade }(\%)=\frac{\text { Massa inicial }- \text { masa final }}{\text { Massa inicial }} \times 100
$$

Aos tratamentos foi aplicada a análise de variância em nível de $5 \%$ de probabilidade $(p<0,05)$ para verificar o efeito da variação da concentração de sorbitol e da temperatura de secagem no teor de água inicial das soluções filmogênicas. As médias foram comparadas pelo teste de Tukey ao nível de $5 \%$ de probabilidade.

Para realizar o ajuste dos modelos matemáticos de razão de umidade foram realizadas análises de regressões não lineares pelo método Quase-Newton.

Para testar o ajuste das Equações 5 a 8 foi determinada a significância dos regressores dos modelos, em nível de $5 \%$ de probabilidade, pelo teste F. Além desse, foram estimados os coeficientes de determinação $\left(\mathrm{R}^{2}\right)$ e o erro médio estimado (SE) (Equação 12):

Em que:

$$
S E=\sqrt{\frac{\sum_{i=1}^{n}\left(Y_{i}-\hat{Y}_{i}\right)^{2}}{G L R}}
$$

$\mathrm{n}=$ o número de observações experimentais; $\mathrm{Y}_{\mathrm{i}}=\mathrm{o}$ i-éssimo valor observado experimentalmente;

$\hat{Y}_{i}=$ o correspondente valor estimado por meio do modelo matemático utilizado; GLR = o grau de liberdade do modelo (número de observações menos o número de parâmetros do modelo).

Fazendo uso da análise de variância (ANOVA) a 5\% de probabilidade, a equação de segunda ordem foi aplicada para explicar a tendência das variáveis respostas $(Y)$ : difusividade efetiva, espessura, permeabilidade ao vapor de água e solubilidade em água, cuja equação geral, de acordo com KHURI e CORNELL (1987) foi:

$$
Y=b_{0}+\sum_{i=1}^{k} b_{i} x_{i}+\sum_{i=1}^{k} b_{i i} x_{i}^{2}+\sum_{i<j} b_{i j} x_{i} x_{j}+\varepsilon
$$

Em que:

$Y=$ função resposta genérica, $x=a$ variável real, $b=$ os coeficientes estimados pelos métodos dos mínimos quadrados, sendo sua significância avaliada pelo valor da probabilidade (p), adotando-se um valor de $p \leq 0,05$ para todos os ensaios, e $\varepsilon=0$ erro experimental.

A adequação do modelo polinomial foi avaliada comparando-se a proporção da variação explicada, isto é, pela análise do coeficiente de determinação ajustado $\left(R_{a j}^{2}\right)$ e pelo método de seleção passo à frente (forward selection) (CHARNET, 1999) até que o valor das somas dos quadrados do erro (SQE) não variasse ou até completar os coeficientes do modelo proposto. Os coeficientes da regressão foram escolhidos de acordo com os valores de probabilidade $\leq 0,05$.

Os gráficos de superfície de resposta foram desenhados por meio do modelo matemático proposto, mantendo-se a resposta em função do eixo $Z$ com eixos $X$ e $Y$ representando os fatores independentes.

Para o desenvolvimento das análises estatísticas e dos gráficos utilizou-se o software Statistic, versão 8.0 (STATSOFT, 2007).

\section{RESULTADOS E DISCUSSÃO}

Na Tabela 2 encontram-se os valores dos teores de água iniciais das soluções filmogênicas e as características físicas dos filmes biodegradáveis elaborados. Pela análise de variância aplicada (Tabela 3), os tratamentos apresentaram diferenças nos seus teores de água iniciais dividindo-se em três grupos que diferem estatisticamente segundo o teste de Tukey ao nível de $5 \%$ de probabilidade $(p<0,05)$. Essa característica mostrou-se independente da temperatura de secagem.

Os tratamentos com $0,2 \%$ de sorbitol apresentaram o maior teor de água médio (76,06\%), 
seguidos por aqueles com 0,1\% e 0,3\% de sorbitol (61,96 e 54,69\%, respectivamente). Tudo leva a acreditar que a concentração de sorbitol influenciou esses dados experimentais pois, segundo GALDEANO (2007), a transformação da SF para filme após sua secagem decorre de interações moleculares, isto é, o plastificante reduz as interações moleculares entre as cadeias adjacentes de amido, aumentando a mobilidade do sistema (GONTARD GUILBERT e CUQ, 1993). Dessa forma, as moléculas de água tornam-se mais sujeitas à ação do calor durante a elaboração das SF, evaporando e reduzindo a umidade final dos filmes formados. Experimentalmente, essa suposição ocorreu com os tratamentos com 0,1\% e 0,3\% de sorbitol. Os teores de água iniciais diminuíram com o aumento da concentração de sorbitol, o que não foi observado nos tratamentos com $0,2 \%$ desse plastificante. Ao contrário, o teor de água aumentou provavelmente chegando a sua maior capacidade de retenção de água. No entanto, o fato desses tratamentos reterem maior quantidade de água na matriz polimérica pode ser devido ao caráter hidrofílico do plastificante, permitindo nessa concentração de sorbitol maior fornecimento de sítios ativos em que as moléculas de água possam ser adsorvidas. De acordo com DONHOWE e FENEMA (1992), quanto maior a afinidade do plastificante pela água ocorre maior intumescimento da matriz polimérica.

\section{TABELA 2 - NÍVEIS DOS TRATAMENTOS E VALORES DO TEOR DE ÁGUA INICIAL ( $X_{0}$, EM BASE SECA) DAS SOLUÇõES FILMOGÊNICAS, DA ESPESSURA, PERMEABILIDADE AO VAPOR DE ÁGUA (PVA) E SOLUBILIDADE DOS FILMES BIODEGRADÁVEIS DE AMIDO DE FRUTA-DE-LOBO EM FUNÇÃO DA CONCENTRAÇÃO DE SORBITOL E TEMPERATURA DE SECAGEM}

\begin{tabular}{ccccccc} 
Tratamento & $\begin{array}{c}\text { Sorbitol } \\
(\%)\end{array}$ & $\begin{array}{c}\text { Temperatura } \\
\left({ }^{\circ} \mathrm{C}\right)\end{array}$ & $\mathrm{x}_{0}\left(\mathrm{~kg} \mathrm{~kg}^{-1}\right)^{*}$ & $\begin{array}{c}\text { Espessura } \\
(\mathrm{mm})\end{array}$ & $\begin{array}{c}\mathrm{Pva}\left(\times 10^{-8}\right) \\
{\left[\mathrm{g}(\mathrm{m} \mathrm{s} \mathrm{Pa})^{-1}\right]}\end{array}$ & $\begin{array}{c}\text { Solubilidade } \\
(\%)\end{array}$ \\
\hline $\mathrm{T}_{1}$ & & 33 & $62,34 \pm 0,22^{\mathrm{b}}$ & $0,047 \pm 0,002$ & $5,209 \pm 0,000$ & $26,81 \pm 0,19$ \\
$\mathrm{~T}_{2}$ & 0,1 & 38 & $61,54 \pm 0,34^{\circ}$ & $0,067 \pm 0,013$ & $6,656 \pm 0,289$ & $26,70 \pm 0,26$ \\
$\mathrm{~T}_{3}$ & & 43 & $62,01 \pm 0,25^{\text {bc }}$ & $0,071 \pm 0,011$ & $8,392 \pm 0,289$ & $26,18 \pm 0,08$ \\
$\mathrm{~T}_{4}$ & & 33 & $75,24 \pm 0,88^{\mathrm{a}}$ & $0,051 \pm 0,001$ & $5,498 \pm 0,289$ & $27,95 \pm 0,02$ \\
$\mathrm{~T}_{5}$ & 0,2 & 38 & $76,99 \pm 0,47^{\mathrm{a}}$ & $0,065 \pm 0,015$ & $7,234 \pm 0,289$ & $27,33 \pm 0,42$ \\
$\mathrm{~T}_{6}$ & & 43 & $75,95 \pm 0,18^{\mathrm{a}}$ & $0,073 \pm 0,004$ & $8,681 \pm 0,868$ & $27,18 \pm 0,13$ \\
$\mathrm{~T}_{7}$ & & 33 & $55,86 \pm 0,14^{\text {d }}$ & $0,067 \pm 0,005$ & $8,392 \pm 0,289$ & $29,02 \pm 0,09$ \\
$\mathrm{~T}_{8}$ & 0,3 & 38 & $54,90 \pm 0,41^{\text {d }}$ & $0,069 \pm 0,007$ & $8,102 \pm 0,579$ & $28,76 \pm 0,06$ \\
$\mathrm{~T}_{9}$ & & 43 & $53,31 \pm 0,50^{\text {d }}$ & $0,069 \pm 0,004$ & $8,102 \pm 0,289$ & $28,29 \pm 0,11$
\end{tabular}

Médias obtidas de três repetições.

Médias seguidas por letras minúsculas iguais na coluna não diferem pelo teste de Tukey ao nível de 5\% de significância.

TABELA 3 - ANÁLISE DE VARIÂNCIA DOS TEORES DE ÁGUA INICIAIS DAS SOLUÇÕES FILMOGÊNICAS ELABORADAS COM AMIDO DE FRUTA-DE-LOBO E SORBITOL

\begin{tabular}{cccccc}
\hline $\begin{array}{c}\text { Causas da } \\
\text { variaçấo }\end{array}$ & $\begin{array}{c}\text { Graus de } \\
\text { liberdade }\end{array}$ & $\begin{array}{c}\text { Soma dos } \\
\text { quadrados }\end{array}$ & $\begin{array}{c}\text { Quadrado } \\
\text { médio }\end{array}$ & Teste F & Valor-p \\
\hline Tratamentos & 8 & 2140,4 & 267,5 & $473,6^{\text {*n }}$ & $<0,001$ \\
Erro & 18 & 10,2 & 0,6 & & \\
\hline Total & 26 & 2150,6 & &
\end{tabular}

** Altamente significativo ao nível de $1 \%$ de probabilidade $(p<0,01)$. 
Observando o perfil das curvas de secagem das SF (Figura 1) verifica-se diferença em relação ao tempo de secagem para as temperaturas utilizadas. Os valores demonstram que a secagem à temperatura de $33^{\circ} \mathrm{C}$ exigiu tempo aproximado de $7 \mathrm{~h}$ para que o teor de água atingisse o equilíbrio. Já a $38^{\circ} \mathrm{C}$ o tempo foi em média de $5,1 \mathrm{~h}$ e no caso da temperatura de $43^{\circ} \mathrm{C}$, o tempo de secagem ficou em torno de $3,8 \mathrm{~h}$.
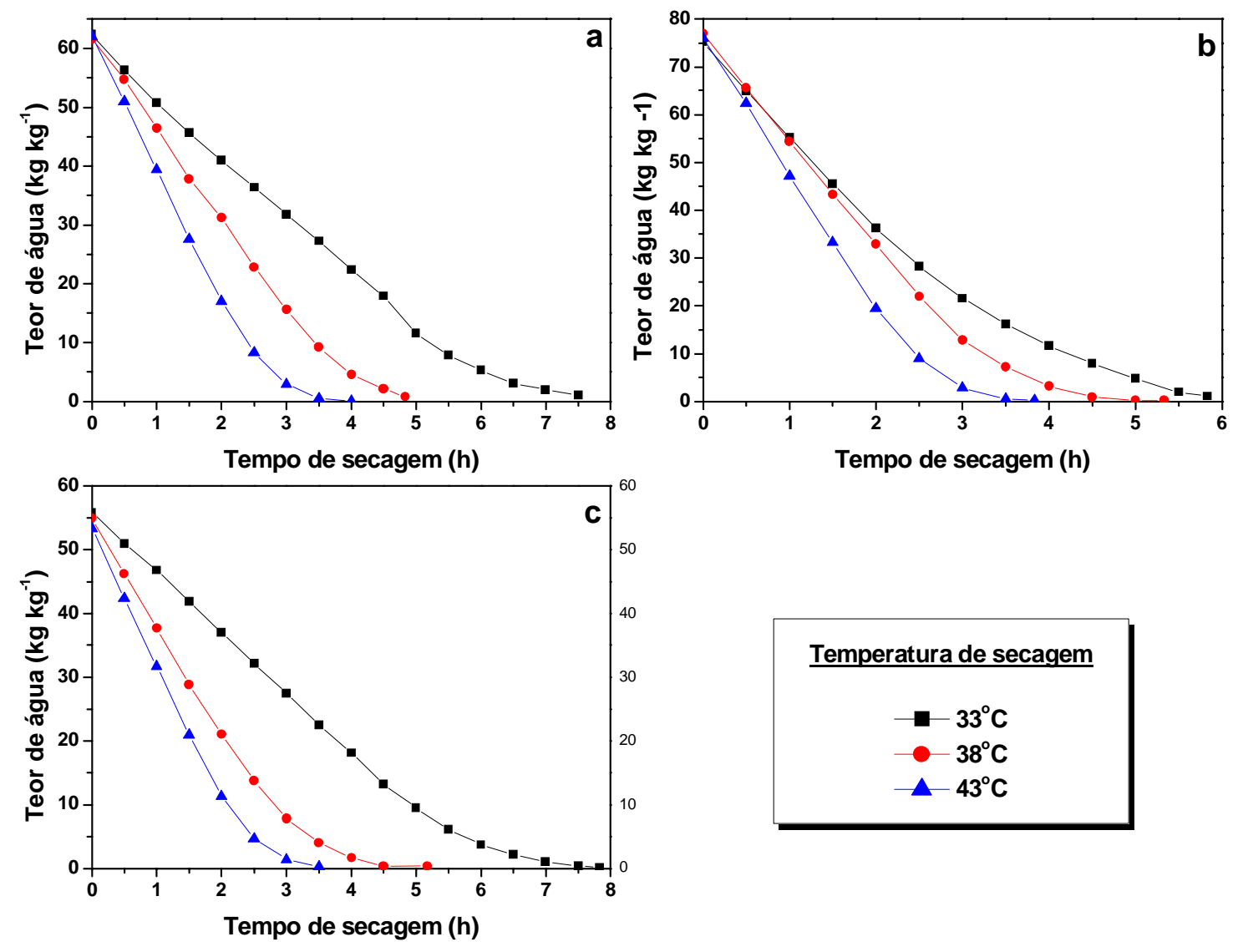

Temperatura de secagem

$-33^{\circ} \mathrm{C}$

$-38^{\circ} \mathrm{C}$

$-43^{\circ} \mathrm{C}$

\section{FIGURA 1 - CURVAS DE SECAGEM DE SOLUÇÕES FILMOGÊNICAS ELABORADAS À BASE DE AMIDO DE FRUTA-DE-LOBO E SORBITOL EM CONCENTRAÇÕES DE a) 0,1\%, b) 0,2\% E c) $0,3 \%$, NAS TEMPERATURAS DE $33,38 \mathrm{E} 43^{\circ} \mathrm{C}$}

O perfil das curvas apresentou redução dos teores de água conforme a temperatura de secagem aumentou, variando entre 0,06 e 1,15 $\mathrm{kg} \mathrm{kg}^{-1}$ (Figura 1). Essas observações podem ser muito importantes na tomada de decisão para a otimização de sistemas de secagem das soluções filmogênicas, assim como na prevenção das características mecânicas dos filmes produzidos durante a secagem. Filmes muito secos enrugam-se ou ficam quebradiços, dificultando sua manipulação e quando muito úmidos pode haver a proliferação de microrganismos nos filmes.

Visto que as soluções filmogênicas apresentam teores de água iniciais diferentes, e a fim de achar modelo matemático preditivo para a secagem, considerou-se o teor de água inicial constante (igual à unidade) e os dados experimentais foram transformados em unidades adimensionais usandose a Equação 2. Os resultados são mostrados em forma de gráficos nas Figuras 2 a 4.

Segundo a análise de variância da Tabela 4, os modelos matemáticos de secagem de Newton, Page, Henderson-Pabis e Midilli se adequaram bem aos dados experimentais de secagem das SF. $O$ teste $\mathrm{F}$ foi muito maior do que do $\mathrm{F}$ tabelado $\left(2,0<\mathrm{F}_{\mathrm{t}}<5\right)$, conferindo confiabilidade de $99 \%$ de ajuste aos modelos. Os correspondentes coeficientes da regressão não linear desses modelos matemáticos estão na Tabela 4. 

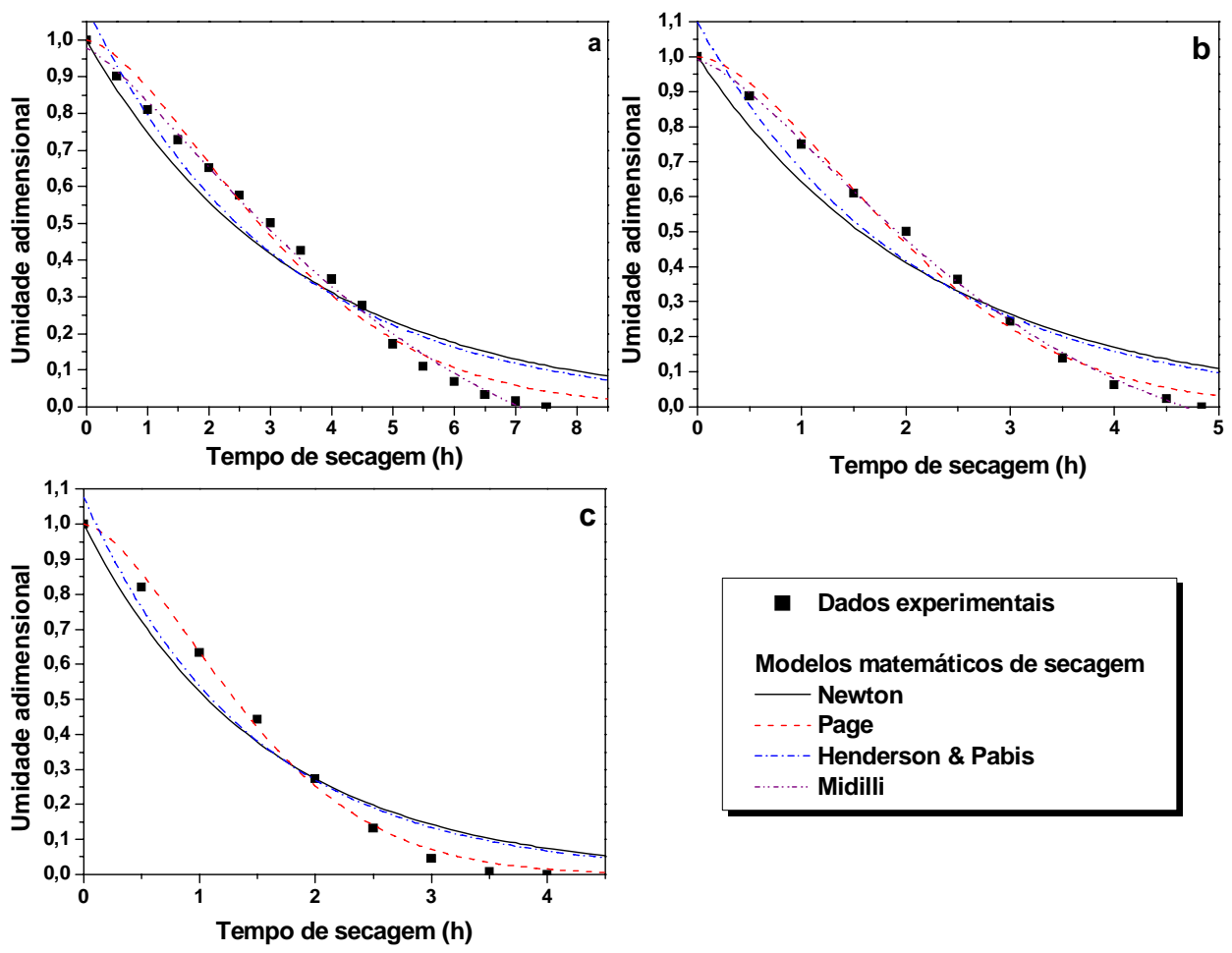

FIGURA 2 - CURVAS DE UMIDADE ADIMENSIONAL DAS SOLUÇÕES FILMOGÊNICAS ELABORADAS COM AMIDO DE FRUTA-DE-LOBO E SORBITOL A 0,1\%, SECAS A a) $33^{\circ} \mathrm{C}$, b) $38^{\circ} \mathrm{C} \mathrm{E} \mathrm{c)} 43^{\circ} \mathrm{C}$
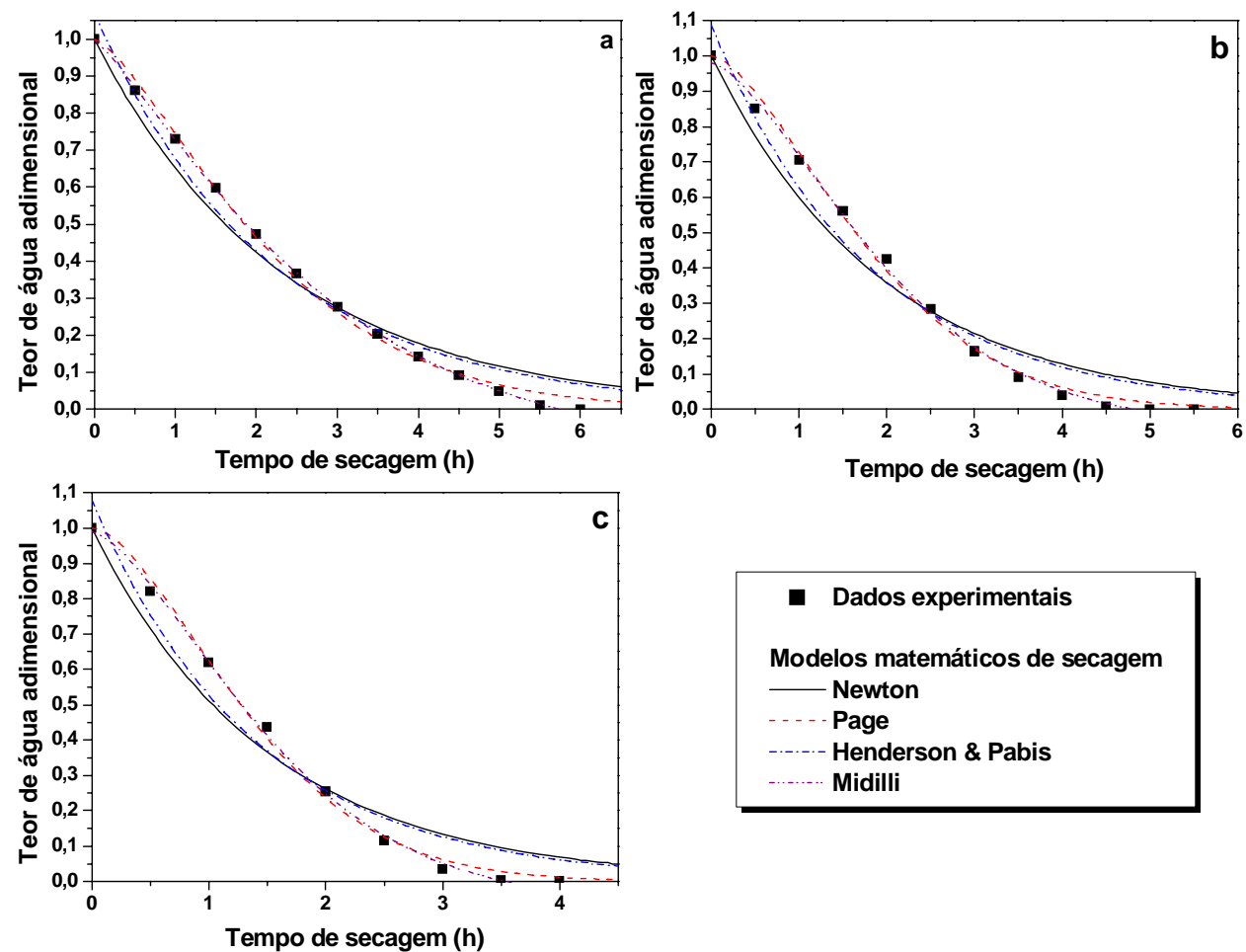

c Dados experimentais

Modelos matemáticos de secagem - Newton Page

Henderson \& Pabis Midilli 

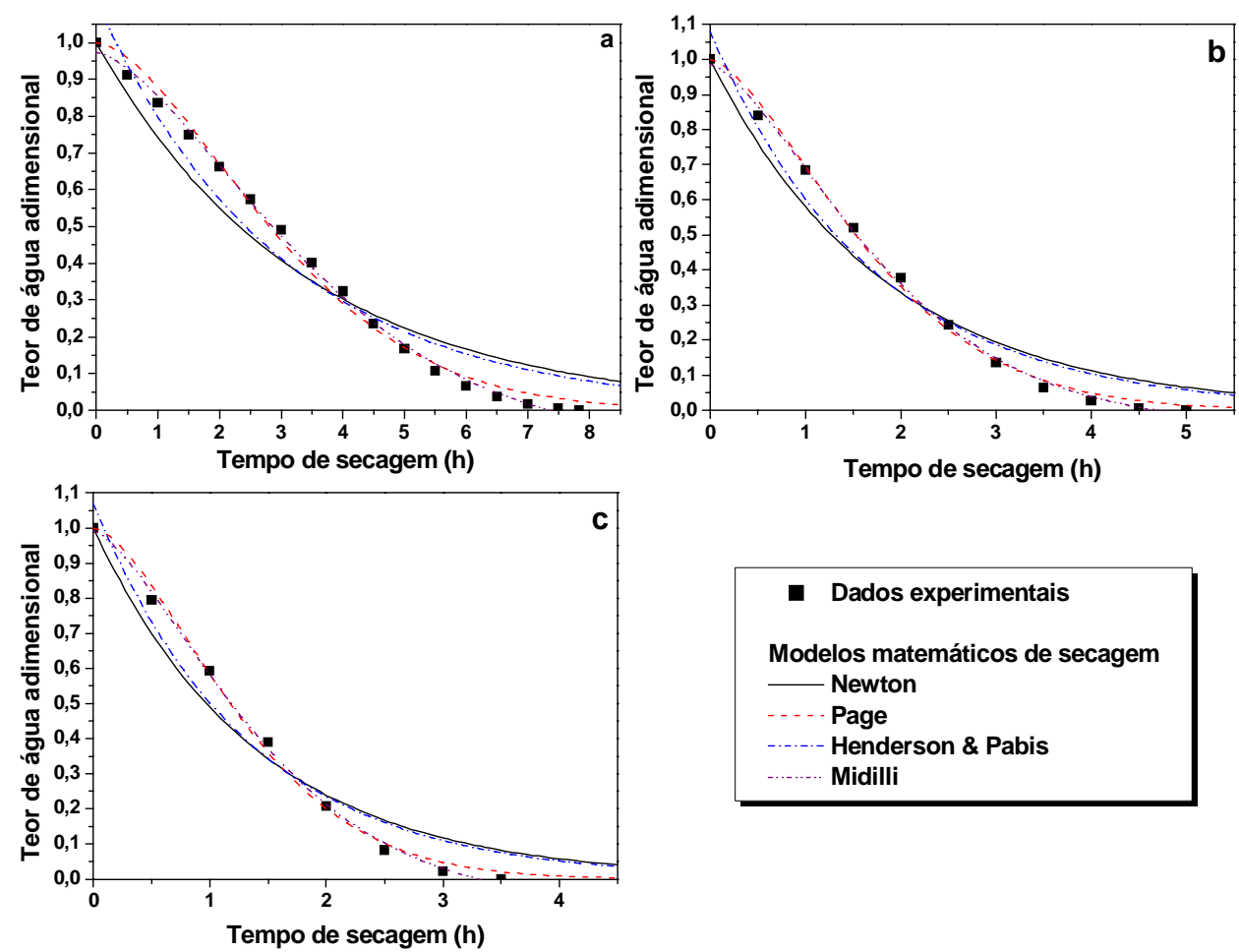

\section{FIGURA 4 - CURVAS DE UMIDADE ADIMENSIONAL DAS SOLUÇÕES FILMOGÊNICAS ELABORADAS COM AMIDO DE FRUTA-DE-LOBO E SORBITOL A 0,3\%, SECAS A a) $33^{\circ} \mathrm{C}$, b) $38^{\circ} \mathrm{C}$ E c) $43^{\circ} \mathrm{C}$}

De acordo com HAIR et al. (2005), o modelo matemático preditivo deve apresentar pequemos valores de erro padrão. Portanto, tudo indica que os modelos de Page e Midilli ajustaram-se adequadamente aos dados experimentais de secagem. Esses modelos apresentaram valores de erro padrão da estimativa da média entre 0,018 e 0,046, inferiores aos obtidos pelos modelos de Newton e Henderson-Pabis (entre 0,058 e 0,091).

Se pelos valores do erro padrão da estimativa foram obtidos resultados satisfatórios com os modelos de Page e Midilli, as Figuras 2 a 4 indicam que as curvas ajustadas pelo modelo de Page afastaram-se dos dados experimentais obtidos em tempos próximos ao final da secagem. Assim, o modelo matemático de Midilli mostrou-se mais adequado para predizer as curvas de secagem de soluções filmogênicas de amido de fruta-de-lobo e sorbitol em concentrações de 0,1 a $0,3 \%$.

O estudo da difusividade efetiva das soluções filmogênicas torna-se importante nos processos de otimização de produção de filmes biodegradáveis. Maiores valores de difusividade efetiva implicam em menores tempos de secagem do material, o que pode diminuir os gastos energéticos. Portanto, torna-se também necessário considerar as propriedades dos filmes formados durante a secagem para que possam ser indicados para aplicações funcionais diferentes.

Sendo o modelo de Midilli o que melhor se ajustou aos dados experimentais de secagem das soluções filmogênicas, com base no parâmetro $\mathrm{k}$ desse modelo matemático e com a ajuda da Equação 9, a difusividade efetiva das soluções filmogênicas foi calculada. Aplicou-se análise de variância para a regressão linear e quadrática com interações a fim de se verificar o efeito dos fatores estudados nas respostas de difusividade efetiva das SF e na espessura, Pva e solubilidade dos filmes biodegradáveis elaborados (Tabela 5). As superfícies de resposta geradas podem ser visualizadas na Figura 5. 


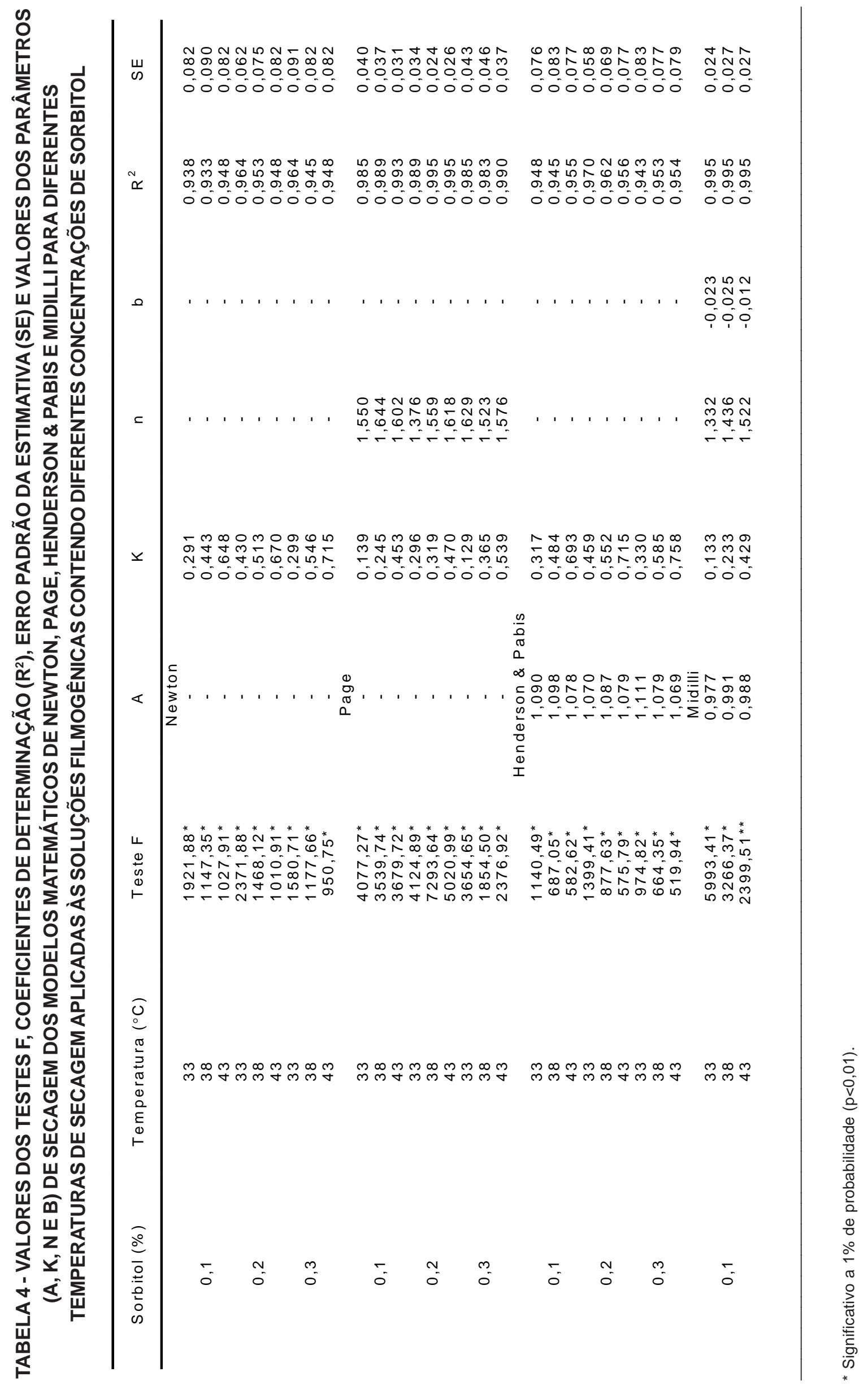


De acordo com a Tabela 5 para a variável resposta difusividade efetiva, o coeficiente de determinação foi de 0,750 , explicando $75 \%$ da variação total da variável resposta em torno da média e 25\% atribuídos aos resíduos.

TABELA 5 - TESTE F, COEFICIENTES DO MODELO DE REGRESSÃO POLINOMIAL (CR) E DE DETERMINAÇÃO AJUSTADO $\left(R^{2}{ }_{A J}\right)$ APLICADOS AOS RESULTADOS DE DIFUSIVIDADE EFETIVA DAS SOLUÇÕES FILMOGÊNICAS, ESPESSURA, PERMEABILIDADE AO VAPOR DE ÁGUA (PVA) E SOLUBILIDADE EM ÁGUA DOS FILMES BIODEGRADÁVEIS DE AMIDO DE FRUTA-DE-LOBO E SORBITOL

\begin{tabular}{|c|c|c|c|c|c|c|c|c|}
\hline \multirow{3}{*}{ Fatores } & \multicolumn{8}{|c|}{ Variável resposta } \\
\hline & \multicolumn{3}{|c|}{ Difusividade efetiva } & Espessura & \multicolumn{2}{|r|}{ Pva } & \multicolumn{2}{|c|}{ Solubilidade } \\
\hline & Teste F & CR & Teste F & CR & $\begin{array}{c}\text { Teste } \\
\mathrm{F}\end{array}$ & CR & Teste F & CR \\
\hline Intercepto & - & $-7,62 \times 10^{-4 \star \star}$ & - & $-8,34 \times 10^{-2 n . s}$ & - & $14 . \overline{9} 8^{\star \star}$ & - & $2,82^{\star \star}$ \\
\hline $\mathrm{S}$ & $47,32^{\star \star}$ & $6,91 \times 10^{-4 \star \star}$ & $0,97^{\text {n.s. }}$ & $4,39 \times 10^{-1 \text { n.s. }}$ & $17,76^{\star \star}$ & $73,21^{\text {* }}$ & $560,52^{\star \star}$ & $1,06^{\star \star}$ \\
\hline$S^{2}$ & - & - & - & - & - & - & - & - \\
\hline $\mathrm{T}$ & $.32,06^{\star *}$ & $2,31 \times 10^{-5 \star \star}$ & $5,42^{*}$ & $3,71 \times 10^{-3 n . s .}$ & $34,82^{\star \star}$ & $0,55^{\star \star}$ & $63,72^{\star \star}$ & $-0,01^{\star \star}$ \\
\hline $\mathrm{T}^{2}$ & - & - & - & - & - & - & - & - \\
\hline \multirow{2}{*}{$\begin{array}{l}\mathrm{S} \times \mathrm{T} \\
\text { Falta de } \\
\text { ajuste } \\
\end{array}$} & - & - & $1,65^{\text {n.s. }}$ & $-1,07 \times 10^{-2 n . s}$ & $17,05^{\star \star}$ & $-1,74^{\star \star}$ & - & - \\
\hline & $6,09 \star \star$ & - & $0,23^{\text {n.s. }}$ & - & $1,44^{\text {n.s. }}$ & - & $1,61^{\text {n.s. }}$ & - \\
\hline $\mathrm{R}_{\mathrm{aj}}^{2}$ & \multicolumn{2}{|r|}{0,750} & \multicolumn{2}{|r|}{0,254} & \multicolumn{2}{|r|}{0,699} & \multicolumn{2}{|c|}{0,954} \\
\hline
\end{tabular}

S = Concentração de sorbitol; $T$ = Temperatura

** Significativo ao nível de 1\% $(p<0,01)$.

n.s. não significativo $(p>0,05)$.

Com relação às variáveis independentes estudadas pode-se perceber que houve influência da concentração de sorbitol e da temperatura de secagem nos valores de $D_{\text {eff }}(p<0,01)$. O modelo matemático gerado foi descrito como:

$$
\text { Difusividade efetiva }\left(D_{\text {eff }}\right)=-7,62 \times 10^{-4}+6,91 \times 10^{-4} S+2,30 \times 10^{-4} T
$$

O efeito positivo linear da concentração de sorbitol e da temperatura evidencia que maiores valores de difusividade efetiva são conseguidos com essas variáveis nos seus níveis superiores. De acordo com Kester e Fenema (1989), a presença do plastificante nos filmes aumenta a sua hidrofilicidade, proporcionando o movimento das cadeias poliméricas e, consequentemente, facilitando o movimento das moléculas que atravessam o filme. Dessa forma, o coeficiente de difusão aumenta e eleva a difusividade efetiva.

A água é o principal componente na elaboração das soluções filmogênicas, o que se pode verificar pelo teor de água inicial dos filmes (de 53,31 a 76,99 $\mathrm{kg} \mathrm{kg}^{-1}$ ). Assim, com a elevação da temperatura de secagem ocorre maior evaporação das moléculas de água, o que aumenta a difusão do vapor de água através da superfície da solução filmogênica. A mesma tendência foi verificada por EL-AOUAR e MURR (2003) e por AZOUBEL et al. (2008). Dessa forma, a elevação da temperatura provoca o aumento da difusividade efetiva, já que essa representa a velocidade com que a água se difunde do interior do material até a sua superfície (OLIVEIRA, OLIVEIRA e PARK, 2006). 

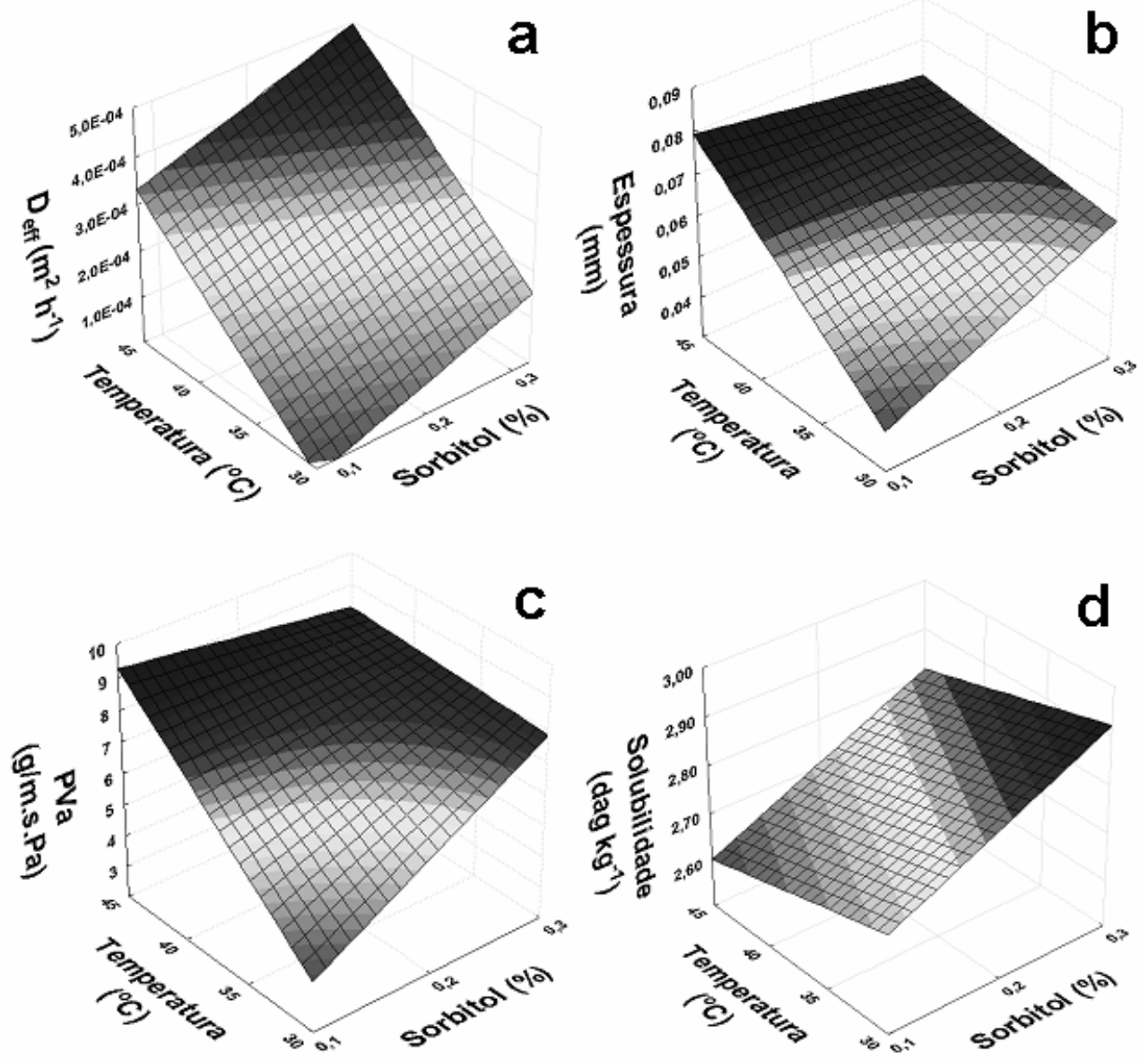

\section{FIGURA 5 - SUPERFÍCIE DE RESPOSTA PARA O EFEITO DA TEMPERATURA DE SECAGEM E DA CONCENTRAÇÃO DE SORBITOL NA a) DIFUSIVIDADE EFETIVA DAS SOLUÇÕES FILMOGÊNICAS, b) ESPESSURA, c) PERMEABILIDADE AO VAPOR DE ÁGUA (PVA) E d) SOLUBILIDADE EM ÁGUA DOS FILMES BIODEGRADÁVEIS ELABORADOS COM AMIDO DE FRUTA-DE-LOBO E SORBITOL}

A espessura influencía as propriedades dos filmes, sendo necessária para definir a homogeneidade do material e permitir comparação entre as propriedades dos mesmos, o que torna importante a determinação desse parâmetro (MALI et al., 2002).

Segundo a análise de variância da Tabela 5, a variação da espessura dos filmes de amido de fruta-de-lobo e sorbitol se deve ao fator temperatura $(p<0,01)$. LAOHAKUNJIT e NOOMHORM (2004) observaram maior influência do plastificante na variação da espessura de filmes à base de amido de arroz e sorbitol e acreditaram que o sorbitol penetra na estrutura do amido formando rede mais forte $\mathrm{e}$ espessa. SHIMAZU, MALI e GROSSMANN. (2007) estudaram filmes de amido de mandioca plastificados com sorbitol e glicerol e também verificaram o aumento da espessura com elevação da concentração de plastificante. Esses autores atribuíram tais resultados ao maior teor de sólidos secos nos filmes que continham maior concentração de plastificante. MOURA (2008) elaborou filmes biodegradáveis de amido de lírio-do-brejo e também constatou aumento da espessura dos filmes com a elevação da concentração do glicerol na matriz polimérica. No entanto, os resultados de espessura dos filmes de fruta-de-lobo não podem ser explicados por meio de modelo matemático uma vez que na mesma Tabela 5 se observa que o coeficiente de determinação ajustado é inferior a 0,26 
( $\mathrm{R}_{\text {aj }}^{2}=0,254$ ), indicando que aproximadamente $74 \%$ da variação da espessura é atribuída a erros sistemáticos e $26 \%$ à temperatura de secagem. Ainda, os coeficientes da regressão aplicada não são significativos $(p>0,05)$ evidenciando que os fatores concentração de sorbitol e temperatura de secagem não influenciaram a espessura dos filmes elaborados com amido de fruta-de-lobo, mantendo-os estatisticamente iguais.

Pela análise de variância da Tabela 5 , os efeitos da concentração de sorbitol, da temperatura de secagem e da interação dos fatores foram altamente significativos $(p<0,01)$ sobre a permeabilidade ao vapor de água dos filmes biodegradáveis. Os fatores apresentaram efeito linear positivo na Pva dos filmes. Assim, a elevação da temperatura de 33 para $43^{\circ} \mathrm{C}$ produz aumento na permeabilidade ao vapor de água de 5,21 para $7,81 \times 10^{-8} \mathrm{~g} \mathrm{~m}^{-1} \mathrm{~s}^{-1} \mathrm{~Pa}^{-1}$, enquanto que o incremento na concentração de sorbitol de $0,1 \%$ para $0,3 \%$ provoca aumento na Pva de 6,75 para $8,20 \times 10^{-8} \mathrm{~g}(\mathrm{~m} \mathrm{~s} \mathrm{~Pa})^{-1}$.

O modelo apresentou bom ajuste aos resultados de Pva dos filmes, sendo considerado significativo e preditivo. Não foi verificada significância da falta de ajuste aos dados experimentais de Pva dos filmes ( $p>005)$. Por meio dos coeficientes de regressão foi possível gerar o seguinte modelo matemático:

$$
\text { Pva }=-14,98+73,21 S+0,55 \mathrm{~T}-1,74 \mathrm{ST}
$$

A Figura 5 apresenta a superfície de resposta para a Pva dos filmes de amido de fruta-de-lobo e sorbitol. Observa-se região de mínimo valor de Pva dos filmes, compreendida na menor concentração de sorbitol $(0,1 \%)$ e menor temperatura de secagem $\left(33^{\circ} \mathrm{C}\right)$. Pode-se notar que em altas concentrações de sorbitol, o efeito da temperatura é desprezível. Em baixas concentrações de sorbitol ocorre maior efeito da elevação da temperatura de secagem no aumento da Pva dos filmes elaborados.

Os resultados encontrados no presente trabalho mostram que quanto maior a concentração de sorbitol das suspensões filmogênicas, maior a permeabilidade ao vapor de água dos filmes elaborados. $O$ uso de sorbitol gerando filmes com maiores valores de Pva também foi observado por Vicentini (2003) ao estudar filmes de amido de mandioca, por Sobral et al. (2001) e Thomazine, Carvalho e Sobra. (2005) em filmes de gelatina. Entretanto, outros autores (PONCE et al., 2005; GALDEANO, 2007) encontraram comportamento contrário: filmes plastificados mostraram menor permeabilidade que os sem plastificantes. De acordo com Martelli et al. (2006), o aumento da Pva dos filmes com maior quantidade de plastificante deve-se ao seu caráter hidrofílico, o que aumenta a sorção de moléculas de água.

Segundo Gontard Guilbert e Cuq (1993), os plastificantes reduzem as interações intermoleculares entre as cadeias adjacentes de amido, aumentando a mobilidade do sistema. Outro fator que afeta a permeabilidade dos filmes é o caráter higroscópico do plastificante (SOBRAL, SANTOS e GARCIA, 2005). Assim, de acordo com Donhowe e Fenema (1992), quanto maior a afinidade do plastificante pela água ocorre maior intumescimento da matriz do filme.

Os resultados de espessura e permeabilidade apresentaram boa correlação positiva entre si $(R=0,6043)$. Acredita-se que com a elevação da temperatura de secagem ocorre maior formação de bolhas de ar no material que causa o aumento da espessura dos filmes. Essas bolhas ocasionam maior porosidade do filme formado, o que torna o material mais permeável ao vapor de água. A elevação da Pva em função do aumento da espessura também foi observado por outros autores (PARK e CHINNAN, 1995; VICENTINI, 2003). Segundo Sobral (1999), esse comportamento é observado em filmes hidrofílicos devido à interação da água com a matriz polimérica. $O$ inchamento da matriz hidrofílica provoca mudanças estruturais que afetam a estrutura dos filmes, facilitando a permeação.

A correlação verificada entre espessura e Pva dos filmes contraria a Lei de Fick de difusão, que afirma que a permeabilidade ao vapor de água deve ser constante com a variação da espessura do material. PARK et al., 1993, trabalhando com filmes de metilcelulose e hidroxipropilcelulose com espessura entre 0,045 e 0,106 mm, observaram que a Pva foi relativamente constante.

A solubilidade em água constitui propriedade importante dos filmes biodegradáveis no que se refere ao seu emprego, pois algumas aplicações requerem insolubilidade em água para manter a integridade do produto (PEREZ-GAGO e KROCHTA, 1999). Além disso, a solubilidade influencía a 
propriedade de barreira ao vapor de água dos filmes biodegradáveis. Para se obter baixa permeabilidade ao vapor de água (enquadra em grande faixa de umidade relativa) torna-se necessária a utilização de material insolúvel ou pouco solúvel em água (FAKHOURI BATISTA e GROSSO, 2003).

A temperatura do processo apresentou efeito linear negativo na solubilidade dos filmes biodegradáveis. Assim, o aumento da temperatura de 33 para $43^{\circ} \mathrm{C}$ produz diminuição na solubilidade média de $26,59 \%$ para $26,11 \%$. Foi observado efeito linear positivo da concentração de sorbitol na solubilidade dos filmes elaborados, sendo que o aumento de 0,1 para $0,3 \%$ na concentração de sorbitol provocou incremento na solubilidade de 26,81 para $29,02 \%$.

Santos (2009) encontrou solubilidade entre de 28,65 a 42,67\% em filmes biodegradáveis elaborados com amido de fruta-de-lobo e glicerol e observou que maiores concentrações do plastificante causaram incremento na solubilidade dos filmes biodegradáveis. Resultado semelhante foi observado no presente trabalho, porém os valores encontrados para solubilidade foram menores, variando de 26,17 a 29,03\% com o aumento na concentração de sorbitol de 0,1 para 0,3\% (Tabela 2). Tápia-Blácido (2006) também verificou que o aumento na concentração de sorbitol de 0,3 para 0,4\% elevou a solubilidade de filmes de farinha de amaranto em 10,55\%. O efeito positivo na solubilidade causado pelo aumento na concentração de sorbitol era esperado devido à maior hidrofilicidade dos filmes biodegradáveis adicionados de agentes plastificantes (MALI et al., 2004). Filmes com maior solubilidade apresentam baixa resistência à água dos filmes plastificados (VICENTINI, 2003), o que pode limitar sua aplicação como material de embalagem.

Por meio da análise de variância realizada observou-se alto grau de ajuste do modelo gerado $\left(R^{2}=95,4 \%\right)$, sendo a falta de ajuste do mesmo não significativa $(p>0,05)$, portanto foi gerada a superfície de resposta para a solubilidade. Por meio da Figura $5 d$ observa-se efeito maior da concentração de sorbitol no aumento da solubilidade dos filmes de amido de fruta-de-lobo, o que confirma a análise de variância já apresentada. A superfície de resposta da solubilidade dos filmes de amido de fruta-de-lobo mostra região de mínimo de solubilidade, que se encontra na concentração de $0,1 \%$ de sorbitol nos filmes secos a $43^{\circ} \mathrm{C}$. Observa-se na Figura $5 \mathrm{~d}$ que quanto maior a concentração de sorbitol e menor a temperatura de secagem das soluções filmogênicas, maior a solubilidade em água dos filmes elaborados. Tápia-Blácido (2006), em estudo de solubilidade de filmes de farinha de amaranto e sorbitol, observou que o aumento da temperatura de secagem dos filmes de 75 a $85^{\circ} \mathrm{C}$ elevou a solubilidade dos mesmos em $20,5 \%$. De acordo com a autora, a elevação da temperatura de secagem dos filmes acima da temperatura de gelatinização da solução filmogênica causa ruptura do grânulo de amido, aumentando a sua solubilidade e a dos filmes formados. Neste trabalho, os filmes foram secos em temperaturas inferiores à temperatura de gelatinização do amido determinada no viscoamilógrafo $\left(69,2^{\circ} \mathrm{C}\right)$, mantendo a estrutura do grânulo de amido e sua baixa solubilidade em água. Assim, filmes com baixa solubilidade foram formados.

Os modelos codificados obtidos a partir dos coeficientes de regressão dos parâmetros estudados, que foram estatisticamente significativos $(p<0,01)$, estão representados pela Equação 16:

$$
\text { Solubilidade }=2,82+1,06 \mathrm{~S}-0,01 \mathrm{~T}
$$

A solubilidade relacionou-se com a permeabilidade ao vapor de água dos filmes biodegradáveis. Para baixos valores de concentração de sorbitol, os filmes biodegradáveis apresentaram menores valores de solubilidade em água e menor permeabilidade ao vapor de água.

\section{CONCLUSÃO}

O teor de água das soluções filmogênicas de amido de fruta-de-lobo foi influenciado pela sua concentração de sorbitol e reduziu-se com o incremento de plastificante. Não foi verificado efeito da temperatura de secagem sobre essa característica. $\mathrm{O}$ aumento da temperatura reduziu o tempo de secagem das soluções filmogênicas. 
O modelo de Midilli mostrou-se o mais adequado para descrever o comportamento das curvas de secagem das soluções filmogências de amido de fruta-de-lobo e sorbitol.

A difusividade efetiva das soluções filmogências foi influenciada linearmente e positivamente pela concentração de sorbitol e pela temperatura de secagem. Não foi constatado efeito desses fatores sobre a espessura dos filmes biodegradáveis elaborados.

Verificou-se efeito linear positivo da concentração de sorbitol e da temperatura de secagem sobre a permeabilidade ao vapor de água dos filmes.

O aumento linear da temperatura de secagem provocou redução dos valores de solubilidade dos filmes, sendo o efeito da concentração de sorbitol positivo sobre essa característica.

\section{ABSTRACT \\ DRYING PROCESS OF FILMOGENIC STARCH SOLUTION OF FRUTA-DE-LOBO (Solanum lycocarpum St. Hil.), AND PHYSICAL PROPERTIES OF STARCH FILMS ACCORDING TO THE PLASTICIZER AND TEMPERATURE}

In the present work was studied the effect of drying temperature (TS) and sorbitol concentration (CS) on the drying characteristics of filmogenic solution (SF) of native "fruta-de-lobo", and on thickness, permeability to water vapor (Paw) and solubility of biodegradable films (FB) prepared. The SF were prepared with $2 \%$ of starch and variations in CS $0.1,0.2$ and $0.3 \%$, and dried in an oven with air circulation at temperatures of 33, 38 and $43^{\circ} \mathrm{C}$. The experimental design was completely randomized factorial design with $3^{2}$, with 3 levels of each of the factors CS and TS. The moisture content of SF was assessed by analysis of variance and means compared by Tukey test. The drying curves were fitted by the empirical models of Newton, Page, Henderson \& Pabis and Midili. Models were obtained for each dependent variable: effective diffusivity (Deff), thickness, Paw and solubility in water by the methodology of response surface. The moisture content ranged from SF with CS, and its increase caused a reduction of this characteristic, not being influenced by TS. The model of Midili obtained a better fit to the experimental data of drying SF. The increase in CS and TS caused an increase in Deff of SF and Paw of FB, and found a linear effect. The solubility of the films studied was affected positively and linearly by increasing the CS and the reduction of TS. There was no effect on the thickness of the films.

KEY-WORDS: DRYING CURVES; EFFECTIVE DIFFUSIVITY; Solanum lycocarpum; FILMOGENIC SOLUTION.

\section{REFERÊNCIAS}

1 AMERICAN SOCIETY FOR TESTING AND MATERIALS. D638M-93: standard test method for tensile properties of thin plastic sheeting. Philadelphia, 1995.

2 ASCHERI, D.P.R.; ANDRADE, C.T.; CARVALHO, C.W.P.; ASCHERI, J.L.R. Obtenção de farinhas mistas pré-gelatinizadas a partir de arroz e bagaço de jabuticaba: efeito das variáveis de extrusão nas propriedades de pasta. Boletim do CEPPA, Curitiba, v. 24, n. 1, p. 115-144, jan./jun., 2006.

3 ASSOCIATION OF OFFICIAL ANALYTICAL CHEMISTS. Official methods of analysis of AOAC International. $17^{\text {th }}$. ed. Washington, 2000. $1094 \mathrm{p}$.

4 AZOUBEL, P.M.; EVANGELISTA, E.C.D.A.; OLIVEIRA, S.B.; SILVA, I.R.A. da; ARAÚJO, A.J. de B. Cinética de secagem da casca de manga 'Tommy Atkins'. In: CONGRESSO BRASILEIRO DE ENGENHARIA QUÍMICA, 17., 2008, Recife. Anais... Recife: Universidade Federal de Pernambuco, 2008. p.1-5.

5 BARONI, A.F.; HUBINGER, M.D. Drying of onion: effects of pretreatments on moisture transport. Drying Technology, v. 16, n. 9/10, p. 2083-2094, 1998.

6 CAMPOS, J.M. O eterno plantio: um reencontro com a natureza. São Paulo: Pensamento, 1994. 250 p.

7 CARVALHO, R.A. Desenvolvimento e caracterização de biofilmes à base de gelatina. 1997. 128 p. (Mestrado em Ciência de Alimentos) - Universidade Estadual de Campinas (UNICAMP), Campinas, 1997.

8 CHARNET, R.; FREIRE, C.A.L.; CHARNET, E.M.R.; BONVINO, H. Análise de modelos de regressão linear com aplicações. Campinas: Editora da UNICAMP, 1999. 356 p.

9 DONHOWE, I.G.; FENNEMA, O.R. The effect of relative humidity gradient on water vapor permeance of lipid and lipidhydrocolloid bilayer films. Journal of the American Oil Chemists' Society, v. 69, n. 11, p. 1081-1087, 1992. 
10 DOYMAZ, I.; PALA, M. The effects of dipping pretreatments on air-drying rates of the seedless grapes. Journal of Food Engineering, Kidlington, v. 52, n. 4, p. 413-417, 2002.

11 EL-AOUAR, Â.A.; MURR, F.E.X. Estudo e modelagem da cinética de desidratação osmótica do mamão formosa (Carica papaya L.). Ciência \& Tecnologia de Alimentos, Campinas, v. 23, n. 1, p. 69-75, 2003.

12 FAKHOURI, F.M.; BATISTA, J.A.; GROSSO, C. Efeito de coberturas comestíveis aplicadas em goiabas in natura (Psidium Guajava L.) I. Desenvolvimento e caracterização de filmes comestíveis de gelatina, triacetina e ácidos graxos. Brazilian Journal of Food Technology, v. 6, n. 2, p. 301-308, 2003.

13 FREITAS, C.S de; RODRIGUES, M.F.; ASCHERI, D.P.R. 2007. Elaboração de biofilme de amido de fruta-de-lobo (Solanum lycocarpum St. Hil.). In: ENCONTRO REGIONAL DA SOCIEDADE BRASILEIRA DE QUÍMICA, 2007. 21., Uberlândia. Anais... Uberlândia: Regional da Sociedade Brasileira de Química, 2007.

14 GALDEANO, M.C. Filmes e laminados biodegradáveis de amido de aveia com diferentes plastificantes, produzidos por casting e extrusão. 2007. 168 p. (Doutorado em Ciência dos Alimentos) - Universidade Estadual de Londrina, Londrina, 2007.

15 GONTARD, N.; GUILBERT, S. Bio-packaging: technology and properties of edible and/or biodegradable material of agricultural origin. Boletim da Sociedade Brasileira de Ciência e Tecnologia de Alimentos (SBCTA), Campinas, v. 30, n. 1, p. 3-15, 1996.

16 GONTARD, N.; GUILBERT, S.; CUQ, J.L. Water and glycerol as plasticers affect mechanical and water vapor barrier properties of an edible wheat gluten film. Journal of Food Science, Chicago, v. 53, n. 1, p. $206-211,1993$.

17 GONTARD, N.; GUILBERT, S.; CUQ, J.L. Edible wheat gluten films: influence of the main process variables on film properties using response surface methodology. Journal of Food Science, Chicago, v. 57, n. 1, p. 190-199. 1992.

18 GORNI, A.A. Aproveitamento de plástico pós-consumo na forma de combustível para altos-fornos e coquerias. Revista Plástico Industrial, v. 8, n. 89, p. 84-100, jan. 2006.

19 HAIR, J.F.; ANDERSON, R.E.; TATHAM, R.L.; BLACK, W.C. Análise multivariada de dados. 5. ed. Porto Alegre: Artmed, 2005.

20 INNOCENTNI-MEI, L.H.; MARIANI, P.D.S.C. Visão geral sobre polímeros ou plásticos ambientalmente degradáveis PADs. Campinas: Unicamp, 2005. 27 p.

21 KESTER, J.J.; FENNEMA, O.R. Edible films and coatings: a review. Food Technology, v. 40, n. 12, p. 47-59, 1986.

22 KESTER, J.J.; FENNEMA, O.R. An edible film of lipids and cellulose ethers: barrier properties to moisture vapor transmission and structural evaluation. Journal of Food Science, Chicago, v. 54, n. 6, p. 1383-1389, 1989.

23 KHURI, A.I.; CORNELL, J.A. Response surfaces. New York: Marcel Dekker, 1987.

24 LAOHAKUNJIT, N.; NOOMHORM, A. Effect of plasticizers on mechanical and barrier properties of rice starch film. Starch/Stärke, v. 56, p. 348-356, 2004.

25 LAROTONDA, F.D.S.; MATSUI, K.N.; SOLDI, V.; LAURINDO, J.B. Biodegradable films made from raw and acetylated cassava starch. Brazilian Archives of Biology and Technology, Curitiba, v. 47, n. 3, p. 477-484, jul. 2004.

26 LOURDIN, D.; COIGNARD, L.; BIZOT, H.; COLONNA, P. Influence of equilibrium relative humidity and plasticizer concentration on the water content and glass transition of starch materials. Polymer: the Chemistry, Physics and Technology of High Polymer, London, v. 38, n. 21, p. 5401-5406, Oct. 1997.

27 MALI, S.; GROSSMANN, M.V.E.; GARCÍA, M.A.; MARTINO, M.M.; ZARITZKY, N.E. Microstructural characterization of yam starch films. Carbohydrate Polymers, v. 50, n. 4, p. 379-386, 2002

28 MALI, S.; GROSSMANN, M.V.E.; GARCÍA, M.A.; MARTINO, M.M.; ZARITZKY, N.E. Barrier, mechanical and optical properties of plasticized yam starch films. Carbohydrate Polymers, Barking, v. 56, n. 2, p. 129-135, 2004.

29 MARTELLI, S.M.; LAURINDO, J.B.; MOORE, G.R.P.; GONDOLFO, C.A.P.; PAES, S.S. Influence of plasticizers on the water sorption isotherms and water vapor permeability of chicken feather keratin films. LWT-Food Science Te-chnology, v. 39, p. 292-301, 2006.

30 MOURA, W. de S. Extração e caracterização do amido do Hedychium coronarium e elaboração de filmes biodegradáveis. 2008. 96 p. (Mestrado em Ciências Moleculares) - Universidade Estadual de Goiás, Anápolis, 2008.

31 OLIVEIRA, R.A. de; OLIVEIRA, W.P. de; PARK, K J. Determinação da difusividade efetiva de raiz de chicória. Engenharia Agrícola, Jaboticabal, v. 26, n. 1, p. 181-189, 2006. 
32 OLIVEIRA-JÚNIOR, E.N.de; SANTOS, C.D.; ABREU, C.M.P; CORRÊA, A.D.; SANTOS, J.Z.L. Alterações pós-colheita da "fruta-de-lobo" (Solanum lycocarpum st. hil.) durante o amadurecimento: análises físico-químicas, químicas e enzimáticas. Revista Brasileira de Fruticultura, Jaboticabal, v. 26, n. 3, p. 410-413, 2004.

33 PARK, H.J.; WELLER, C.L.; VERGANO, P.J.; TESTIN, R.F. Permeability and mechanical properties of cellulose-based edible films. Journal of Food Science, Chicago, v. 58, n. 6, p. 1361-1364, 1993.

34 PARK, H.J.; CHINNAN, M.S. Gas and water vapor barrier properties of edible films from protein and cellulosic materials. Journal of Food Engineering, v. 25, p. 497-507, 1995.

35 PEREZ-GAGO, M.P.; KROCHTA, J.M. Water vapor permeability of whey protein emulsion films as affected by pH. Journal of Food Science, Chicago, v. 64, n. 4, p. 695, 1999.

36 PONCE, P.; PARRA, D.F.; CARR, L.G.; SATO, J.S.; LUGÃO, A.B. Influência da radiação ionizante e do uso de plastificantes nas propriedades mecânicas e de barreira de filmes biodegradáveis. In: INTERNATIONAL NUCLEAR ATLANTIC CONFERENCE; ENCONTRO NACIONAL DE APLICACOES NUCLEARES, Santos, SP. Anais... São Paulo: ABEN, 2005.

37 SANTOS, A.P. Extração e caracterização do amido do fruto-de-lobo (Solanum lycocarpum St. Hil) e elaboração de filmes biodegradáveis. 2009. 93 p. (Mestrado em Ciências Moleculares) - Universidade Estadual de Goiás, Anápolis, 2009.

38 SHIMAZU, A.A.; MALI, S.; GROSSMANN, M.V.E. Efeitos plastificante e antiplastificante do glicerol e do sorbitol em filmes biodegradáveis de amido de mandioca. Ciências Agrárias, Londrina, v. 28, n. 1, p. 79-88, 2007.

39 SILVA, J.A.; SILVA, D.B.; JUNQUEIRA, N.T.V.; ANDRADE, L.R.M. Frutas nativas dos cerrados. Brasília: EMBRAPA, 1994. $166 \mathrm{p}$.

40 SOBRAL, P.J.A. Propriedades funcionais de biofilmes de gelatina em função da espessura. Ciência \& Engenharia, Uberlândia, v. 8, n. 1, p. 60-67, 1999

41 SOBRAL, P.J.A.; MENEGALLI, F.C.; HUBINGER, M.D.; ROQUES, M.A. Mechanical, water vapor barrier and thermal properties of gelatin based edible films. Food Hydrocolloids, v. 15, n. 4-6, p. 423-432, 2001.

42 SOBRAL, P.J.A.; SANTOS, J.S. dos; GARCIA, F.T. Effect of protein and plasticizer concentrations in film forming solutions on physical properties of edible films based on muscle proteins of a Thai Tilapia. Journal of Food Engineering, Oxford, v. 70, n. 1, p. 93-100, 2005.

43 STATSOFT: statistics [computer program]. Versão 8.0. Tulsa: StatSoft; 2007.

44 TÁPIA-BLÁCIDO, D.R. Filmes à base de derivados do amaranto para uso em alimentos. 2006.351 p. (Doutorado em Engenharia de Alimentos) - Universidade Estadual de Campinas, Campinas, 2006.

45 THIRÉ, R.M.S.M; SIMÃO, R.A.; ARAÚJO, P.J.G; ACHETE, C.A. Redução da hidrofilicidade de filmes biodegradáveis à base de amido por meio de polimerização por plasma. Polímeros: Ciência e Tecnologia, Rio de Janeiro, v. 14, n. 1, p. 57-62, 2004.

46 THOMAZINE, M.; CARVALHO, R.A.; SOBRAL, P.J.A. Physical properties of gelatin films plasticized by blends of glycerol and sorbitol. Journal of Food Science, Chicago, v. 70, p. 172-176, 2005.

47 TORRES, J. A. Edible films and coatings from proteins. In: HETTIARACHCHY, N. S.; ZIEGLER, G. R. (Eds.). Protein functionality in food systems. New York: Marcel Dekker, 1994. p. 467-507.

48 VICENTINI, N.M. Elaboração e caracterização de filmes comestíveis à base de fécula de mandioca para uso em pós-colheita. 2003. 198 f. (Doutorado em Agronomia) - Faculdade de Ciências Agronômicas, Universidade Estadual Paulista, Botucatu, 2003.

49 VILPOUX, O.; AVÉROUS, L. Plásticos à base de amido. In: TECNOLOGIA, usos e potencialidades de tuberosas amiláceas Latino Americanas. São Paulo: Fundação Cargill, 2003. p. 499-529. (Collection Culturas de Tuberosas Latinoamericanas).

\section{AGRADECIMENTOS}

Os autores agradecem à Fundação de Amparo à Pesquisa do Estado de Goiás (FAPEG) pelo apoio financeiro a essa pesquisa e à Coordenação de Aperfeiçoamento do Pessoal de Nível Superior (CAPES) pelo financiamento da pesquisa por meio dos recursos do Programa Especial e do Procad. 